\title{
Place Memory Masyarakat pada Bangunan Cagar Budaya di Kota Palopo
}

\author{
Nurhijrah dan Amiruddin Akbar Fisu \\ Fakultas Teknik, Universitas Andi Djemma Palopo \\ Nurhijrah.rie@gmail.com
}

\begin{abstract}
ABSTRAK
Penelitian ini bertujuan untuk mengetahui sejauh mana masyarakat dapat berpartisipasi dalam usaha pelestarian cagar budaya di Kota Palopo. Partisipasi masyarakat diukur berdasarkan keterikatannya secara kognisi terhadap bangunanbangunan cagar budaya di Kota Palopo. Keterikatan secara kognisi terlihat dari bagaimana masyarakat dapat mengingat kembali bagaimana karakteristik bangunan cagar budaya yang ada di Kota Palopo (place memory). Data dikumpulkan dengan teknik wawancara dan dianalisis dengan teknik analisis konten. Dari hasil analisis diketahui bahwa bentuk place memory masyarakat Kota Palopo terhadap bangunan cagar budaya dapat diketagorikan menjadi: lokasi bangunan, fungsi bangunan, karakteristik fisik bangunan. Hasil penelitian menunjukkan bahwa masyarakat Kota Palopo memiliki keterikatan terhadap bangunan cagar budaya yang ditunjukkan dengan adanya usaha untuk pelestatian. Oleh karena itu, diharapkan hasil penelitian ini dapat menjadi salah satu pertimbangan untuk pelestarian bagunan cagar budaya di Kota Palopo.
\end{abstract}

Kata kunci: place, place memory, bangunan cagar budaya

\begin{abstract}
This study aims to determine the extent to which people can participate in efforts to preserve cultural heritage in the city of Palopo. Community participation is measured based on their cognition attachment to cultural heritage buildings in Palopo City. Cognition can be seen from how people can recall how the characteristics of cultural heritage buildings in Palopo City (place memory). Data were collected by interview technique and analyzed by the content analysis technique. The analysis results show that the form of place memory of the Palopo City community towards cultural heritage buildings can be categorized into the location of the building, the function of the building, the physical characteristics of the building. The attachment of the Palopo City community towards cultural heritage buildings is evidenced by the efforts to preserve. Therefore, it is hoped that the results of this study can be one of the considerations for the preservation of cultural heritage buildings in Palopo City.
\end{abstract}

Keywords: place, place memory, cultural heritage buildings

\section{Pendahuluan}

Kota Palopo merupakan salah satu kota yang termasuk dalam Jaringan Kota Pusaka Indonesia. Terdapat beberapa bangunan cagar budaya di Kota Palopo yang merupakan tinggalan dari masa Kedatuan Luwu dan Kolonial Belanda. Saat ini beberapa bangunan peninggalan tersebut masih bertahan, walaupun beberapa beralih fungsi. Beberapa dari bangunan peninggalan tersebut mengalami kerusakan bahkan sudah kehilangan jejak, akibat kemajuan pembangunan kota yang disertai dengan kurangnya 
kesadaran akan pelestarian. Padahal peninggalan bangunan-bangunan tersebut merupakan cagar budaya yang menjadi benang merah antara pembangunan masa lalu dan masa akan datang.

Pelestarian cagar budaya dalam suatu kota merupakan suatu bagian dari strategi budaya yang bertujuan untuk melindungi, mempertahankan dan membentuk karakter kota. Menurut UU RI No. 11 Tahun 2010 tentang Cagar Budaya, pelestarian adalah upaya dinamis untuk mempertahankan keberadaan Cagar Budaya dan nilainya dengan cara melindungi, mengembangkan dan memanfaatkannya.

Salah satu usaha pelestarian cagar budaya yang efektif ialah dengan menyertakan masyarakat lokal. Langkah penyertaan masyarakat dalam upaya pelestarian sudah pernah diterapkan oleh UNESCO. Partisipasi masyarakat dalam usaha pelestarian dapat meningkatkan kesadaran masyarakat itu sendiri akan pentingnya keberadaan bangunan cagar budaya.

Masyarakat lokal akan berpartisipasi dalam dalam pemeliharaan suatu cagar budaya apabila memiliki keterikatan dengan tempat tersebut (Lewicka, 2005). Adanya hubungan antara tempat dan sejarah nenek moyang, membuat seseorang ingin melindungi tempat tersebut, sebagai bagian dari upaya untuk mempertahankan identitas diri. Salah satu bentuk keterikatan seseorang terhadap cagar budaya ialah adanya ingatan, kepercayaan, pemaknaan dan pengetahuan terhadap suatu tempat tertentu, sehingga menjadikan tempat tersebut penting bagi dirinya

Melalui penelitian ini, peneliti bertujuan untuk mengetahui sejauh mana masyarakat dapat berpartisipasi dalam usaha pelestarian cagar budaya di Kota Palopo. Partisipasi masyarakat akan diukur berdasarkan keterikatannya secara kognisi terhadap bangunan-bangunan cagar budaya di Kota Palopo. Keterikatan secara kognisi terlihat dari bagaimana masyarakat dapat mengingat kembali bagaimana karakteristik bangunan cagar budaya yang ada di Kota Palopo (place memory).

Penelitian memori kolektif biasanya digunakan untuk mengetahui sejarah nasional atau sejarah dunia. Namun pada penelitian ini hanya spesifik pada suatu tempat yaitu kota dan bangunan cagar budayanya, sehingga disebut place memory (Lewicka, 2008). Kajian mengenai memori terhadap suatu tempat bersejarah telah dilakukan oleh beberapa peneliti sebelumnya. Akbar, dkk. (2017) dan Utami (2004) menggunakan memori kolektif masyarakat untuk mengidentifikasi bangunan bersejarah, namun tidak melihat hubungan antara subjek (orang) dengan memori yang terbentuk

Terdapat beberapa penelitian yang telah menjelaskan prediktor yang mempengaruhi memori seseorang suatu tempat bersejarah. Lewicka (2008) memahami bahwa faktor etnis bias, usia dan lama tinggal seseorang mempengaruhi seberapa banyak memori seseorang terhadap suatu tempat. Sedangkan pada kasus lainnya, Nurhijrah (2016) menyebutkan bahwa kedekatan tempat tinggal dan adanya hubungan keluarga seseorang dengan tempat berhubungan dengan memorinya.

Dari sejumlah penelitian tersebut, belum diketahui bagaimana karakteristik bangunan secara khusus yang diingat oleh masyarakat, serta bagaimana prediktor place memory mempengaruhi ingatan seseorang terhadap suatu tempat bersejarah. Oleh karena itu, penelitian ini akan mengeksplorasi karakteristik bangunan cagar budaya yang diingat oleh masyarakat, serta bagaimana masyarakat memaknai bangunan tersebut sebagai bagian dari dirinya dan keluarganya.

\section{Bahan dan Metode}

\subsection{Jenis Penelitian}

Penelitian ini dilakukan dengan metode kualitatif-eksploratif. Penelitian dilakukan dengan mencari tahu bagaimana bagaimana masyarakat dapat mengingat kembali 
bagaimana karakteristik bangunan cagar budaya yang ada di Kota Palopo (place memory) dan pemaknaan masyarakat terhadap bangunan cagar budaya tersebut.

\subsection{Lokasi dan Waktu Penelitian}

Penelitian dilakukan di seluruh wilayah administratif Kota Palopo. Walaupun dalam sejarahnya, wilayah Kedatuan Luwu tidak hanya sebatas wilayah Kota Palopo, namun Kota Palopo merupakan pusat kegiatan pemerintahan dan ekonomi pada waktu itu. Sehingga wilayah penelitian hanya dibatasi dalam wilayah administratif Kota Palopo dengan asumsi bahwa lebih banyak bangunan cagar budaya yang berlokasi di Kota Palopo.

\subsection{Informan Penelitian}

Informan penelitian dipilih dengan dengan kriteria sebagai berikut:

a. Masyarakat yang berdomisili di Kota Palopo

b. Mengetahui atau mengenal minimal satu bangunan cagar budaya di Kota Palopo

c. Usia 20 tahun keatas, dengan asumsi sudah bisa memberikan informasi yang dibutuhkan.

\subsection{Teknik Pengumpulan Data}

Berdasarkan tujuan penelitian, teknik pengumpulan data dilakukan dengan cara wawancara dan pengamatan lapangan.

a. Teknik pengamatan lapangan, yaitu melakukan pengamatan secara langsung terhadap kondisi pada obyek penelitian. Pengambilan data dilakukan dengan membuat catatan-catatan dan foto yang dapat mendukung pada tahap analisis.

b. Teknik wawancara, yaitu dengan melakukan tanya jawab langsung dengan informan. Informan akan dipersilahkan untuk menceritakan apa yang diingat dari bangunan cagar budaya yang ada di Kota Palopo.

Wawancara dilakukan kepada 25 orang informan dengan tahapan sebagai berikut:

1) Menanyakan kepada informan mengenai daftar bangunan cagar budaya yang diketahui.

2) Memperlihatkan foto bangunan cagar budaya dan meminta untuk mengidentifikasi bagian bangunan yang diingat.

\subsection{Teknik Analisis Data}

Data yang telah dikumpulkan dari sumber primer dan sekunder dianalisis dengan teknik analisis konten (isi). Semua hasil wawancara dengan informan dituliskan ulang secara verbatim, kemudian dikelompokkan berdasarkan tujuan analisis. Analisis konten dilakukan dengan metode koding yang digunakan untuk mendapatkan kata atau frase yang menentukan adanya fakta yang menonjol, menangkap esensi fakta dari sejumlah kumpulan bahasa atau data (Saldaña, 2015).

\section{Hasil dan Diskusi}

\subsection{Bangunan Cagar Budaya di Kota Palopo}

Keberadaan bangunan cagar budaya di Kota Palopo merupakan bukti sejarah dari masuknya agama Islam di Kedatuan Luwu dan kehadiran Kolonial Belanda pada masa pra dan pasca kemerdekaan di Kota Palopo. Bangunan-bangunan tersebut mencerminkan gaya arsitektur bangunan gedung sesuai jamannya. Berdasarkan Peraturan Daerah Kota 
Palopo No. 08 Tahun 2014 Tentang Pelestarian dan Pengelolaan Cagar Budaya di Kota Palopo yang termasuk bangunan cagar budaya di Kota Palopo ialah sebagai berikut:

Tabel 1. Daftar Bangunan Cagar Budaya di Kota Palopo

\begin{tabular}{|c|c|c|c|}
\hline No & Nama & Tahun & Kategori \\
\hline 1 & Istana Datu Luwu & 1922 & \\
\hline 2 & Masjid Djami Tua & 1603 & Publik \\
\hline 3 & Gereja Pniel & 1923 & \\
\hline 4 & Kantor Dinas Perhubungan & 1940 & \\
\hline 5 & Gedung Balaikota & data & \\
\hline 6 & Kantor Pos & 1924 & \\
\hline 7 & Kantor LVRI & 1925 & \\
\hline 8 & Kantor Eks Bea Cukai & 1930 & \\
\hline 9 & Kantor Eks RS Sawerigading & 1920 & \\
\hline 10 & Rumah tinggal Pak Sabani & 1945 & \\
\hline 11 & Rujab Wakil Walikota & 1940 & \\
\hline
\end{tabular}




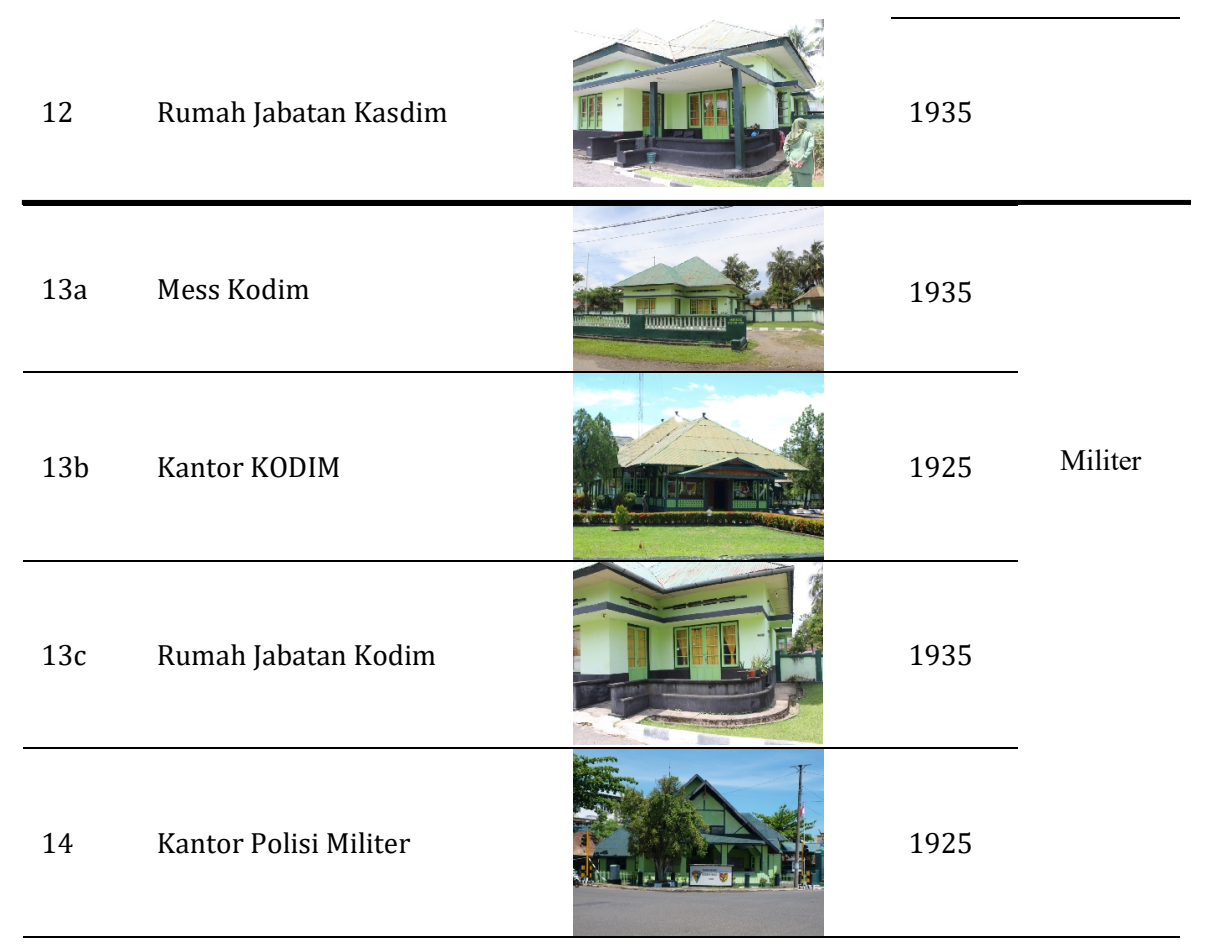

Sumber: Perda Kota Palopo No. 08 Tahun 2014)

\subsection{Place Memory Masyarakat pada Bangunan Cagar Budaya}

Berdasarkan tujuannya, penelitian ini menjelaskan bentuk place memory masyarakat Kota Palopo pada bangunan cagar budaya. Dari hasil analisis, bentuk place memory masyarakat dapat dijelaskan dalam beberapa kategori sebagai berikut:

\section{Lokasi Bangunan}

Pada beberapa kota di Indonesia, pusat kawasan bangunan kolonial cenderung berbeda dengan pusat keraton atau kerajaan (Damayanti, 2005). Pusat kota pada masa keraton atau kerajaan berada di sekitar istana dan kemudian dikelilingi oleh bangunan penting lainnya. Saat masuk masa Kolonial, terdapat kecenderungan dari pemerintah kolonial Belanda untuk membentuk pusat kota baru demi menunjukkan eksistensi kekuasannya.

Dari peta lokasi bangunan cagar budaya di Kota Palopo (Gambar 1) ditunjukkan bahawa bangunan cagar budaya peninggalan masa kolonial cenderung berpusat di satu kawasan, kecuali bangunan eks Bea Cukai yang berlokasi di dekat pelabuhan yang mana merupakan pusat kegiatan perekonomian dari dulu hingga sekarang. Lokasi bangunan cagar budaya ini menunjukkan pusat peradaban pertama di wilayah Kota Palopo, yang mana berada di sekitar Istana Kedatuan Luwu dan Masjid Djami Palopo. Saat ini, lokasi tersebut dikenal sebagai Kawasan Kota Tua di Kota Palopo.

Dari hasil analisis konten yang telah dilakukan, diketahui bahwa faktor lokasi dari bangunan cagar budaya berpengaruh terhadap place memory masyarakat. Tidak satupun dari informan yang menyebutkan bangunan Eks Bea Cukai sebagai salah satu bangunan cagar budaya di Kota Palopo. Selanjutnya peneliti mencoba memberikan informasi bahwa bangunan tersebut termasuk bangunan cagar budaya dan memperlihatkan foto bangunannya lalu mencoba mencari tahu apakah masyarakat dapat mengingat fungsi bangunan tersebut di masa lalu, namun tidak satu pun informan yang dapat memberikan informasi mengenai bangunan tersebut. 
Hal ini berkaitan dengan faktor proximitas individu terhadap suatu tempat. Semakin dekat tempat tinggal seseorang dengan suatu tempat, maka tingkat keterikatannya secara kognisi pun semakin tinggi (Nurhijrah, 2016). Faktor proximitas ini berhubungan dengan intensitas kunjungan dan kefamiliaritas. Adapun sebaran lokasi bangunan cagar budaya tesebut dapat dilihat pada peta lokasi di bawah ini:

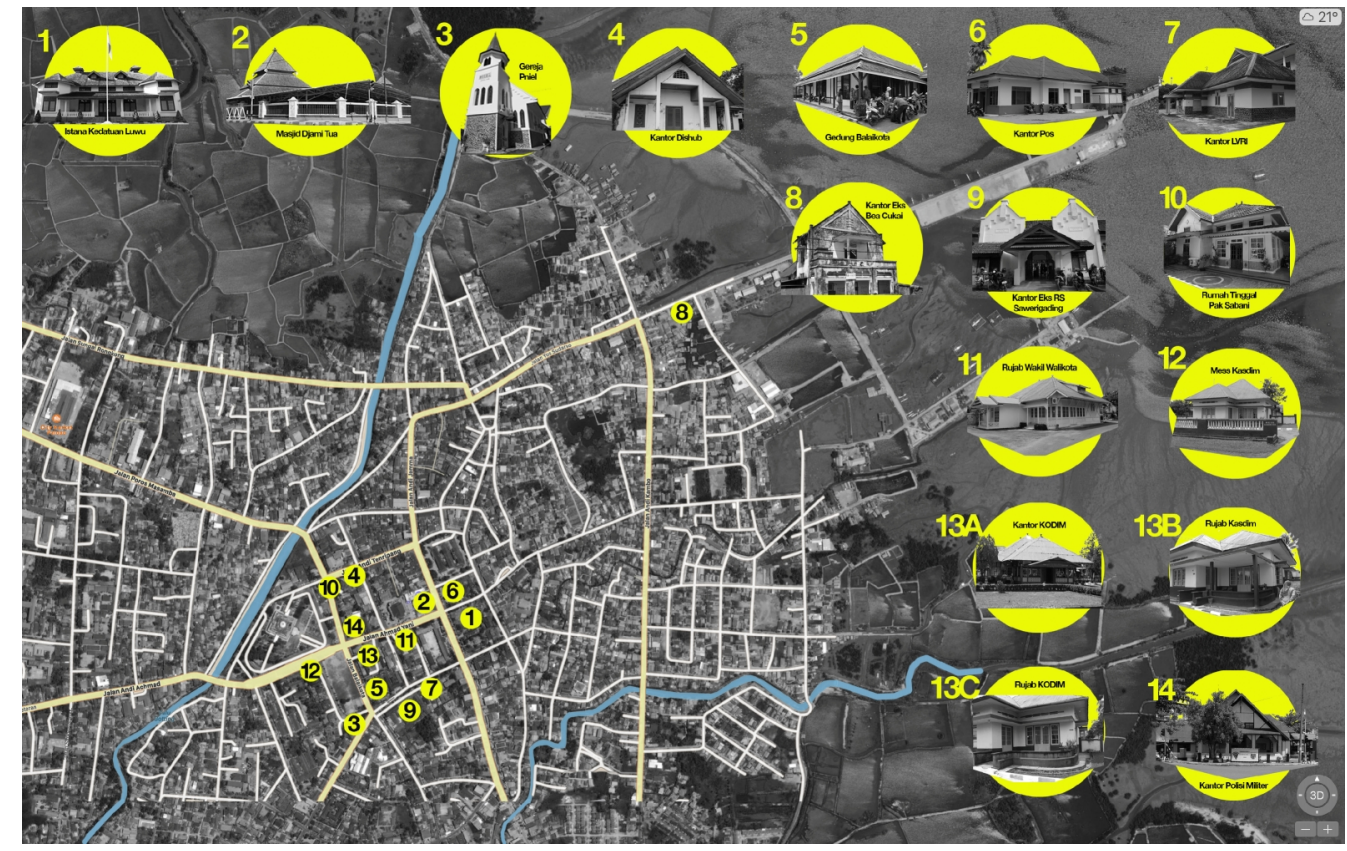

Gambar 1. Peta Lokasi Bangunan Cagar Budaya di Kota Palopo (Sumber: Hasil Analisis, 2019)

\section{Fungsi Bangunan}

Pada Tabel 1, bangunan cagar budaya telah dikategorikan berdasarkan funginya, yaitu: fungsi publik, fungsi privat dan fungsi militer. Dari hasil analisis, diketahui bahwa masyarakat lebih banyak mengetahui informasi mengenai bangunan dengan fungsi publik, seperti: Masjid Djami, Istana Kedatuan Luwu, dan Gereja Pniel. Bangunan tersebut dianggap dekat dengan kehidupan sehari-hari masyarakat karena fungsinya sebagai tempat ibadah dan sebagai ikon dari Kota Palopo. Hal ini pun yang membuat ingatan masyarakat mengenai tempat tersebut menjadi lebih jelas dari masa ke masa. Berikut beberapa pernyataan informan:

\section{“.....dulu waktu sekolah, kita sering menari di Istana terus nanti sholatnya di} Masjid Djami...” Aisyah, 45 tahun.

“.....waktu sekolah, kami sering latihan menari di istana, acara-acara 17-an juga sering diadakan di sana, jadi seingat saya bentuk bangunannya itu tidak ada yang berubah sampai sekarang....." Nasirah, 60 tahun.

Dari pernyataan informan tersebut diatas sangat jelas bahwa fungsi publik dari bangunan serta intensitas kunjungan membuat bangunan tersebut dimaknai lebih oleh masyarakat Kota Palopo. Adapun pada bangunan dengan fungsi militer, tidak ada informan yang dapat memberikan informasi lebih detail mengenai bangunan tersebut, sekedar hanya menyebutkan bahwa bangunan tersebut juga termasuk bangunan cagar budaya. Hal ini pun terkait dengan faktor lokasi di mana bangunan cagar budaya dengan 
fungsi militer berada pada kawasan militer yang tertutup sehingga masyarakat biasa tidak pernah berkunjung.

\section{Karakteristik Bangunan}

Pada beberapa penelitian sebelumnya disebutkan bahwa keterikatan masyarakat pada suatu tempat dari aspek kognisi hanya dipengaruhi oleh makna yang diberikan oleh tempat bukan dari bentuk fisiknya (Stedman, 2003; Nurhijrah, 2016). Namun pada penelitian ini diketahui bahwa informan mengidentifikasi suatu bangunan sebagai bangunan cagar budaya ialah dengan melihat karakteristik fisik bangunannya. Seperti yang diutarakan oleh salah satu informan sebagai berikut:

"Kalau seperti ini atapnya itu bangunan tua. Cuma rumah-rumah dulu begini atapnya..... terus bangunan dulu-dulu bentuknya, tidak sama dengan bangunan sekarang, kusennya itu besar-besar, jendelanya juga..." Aisyah, 45 tahun.

"Kalau Kantor Pos itu, kacanya saja yang diubah sama dulunya hanya pakai jalusi kayu yang aslinya." Usman, 67 Tahun.

Dari penuturan beberapa informan diatas, diketahui bahwa karakteristik bangunan yang dianggap sebagai suatu penanda berubah tidaknya suatu bangunan cagar budaya ialah bentuk atap dan kusen jendela. Studi mengenai karakteristik fisik bangunan cagar budaya biasanya dilakukan dengan melihat dokumentasi lama dan dilakukan interpretasi terhdapnya. Pada penelitian ini, karakteristik fisik suatu bangunan digambarkan dari pernyataan atau ingatan masyarakat. Hal ini lah yang menjelaskan bagaimana masyarakat memaknai suatu tempat dengan memiliki ingatan terhadapnya (place memory).
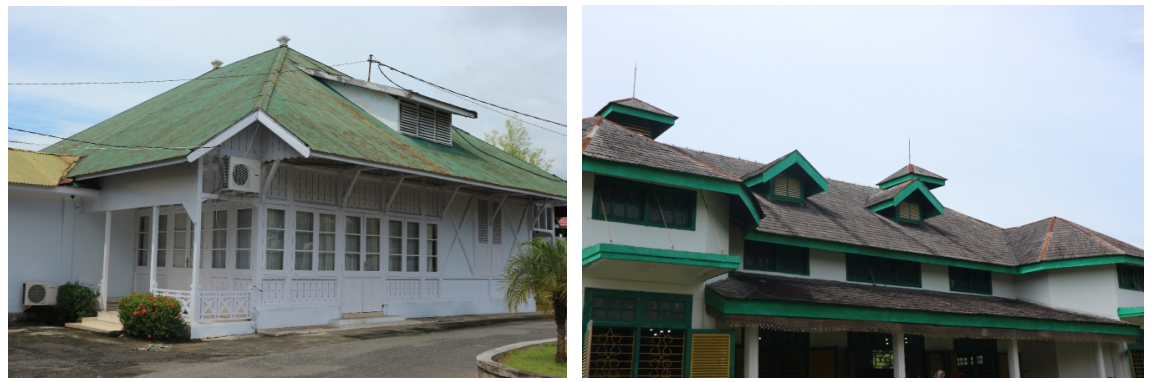

Gambar 2. Bantuk Atap Bangunan Cagar Budaya yang diidentifikasi oleh masyarakat (Sumber: Dokumentasi Peneliti, 2019)

Keterikatan individu terhadap suatu tempat bernilai budaya ditunjukkan dari aspek afeksi yaitu keinginan untuk melindungi tempat tersebut (Lewicka, 2005). Beberapa informan menunjukkan keinginan tersebut dari beberapa pernyataan sebagai berikut

“.......lebih baik bangunan itu dikembangkan, jangan dirusak. Apalagi istana jagan diganggu. Istana itu simbol Luwu, namun sekarang kesan tersebut hilang, sudah tidak segan orang sekarang." Erna, 40 tahun.

"Bangunan cagar budaya itu perlu dikembangkan namun tidak menghilangkan ciri khasnya, seperti di tanah suci." Ida, 60 Tahun. 
Place memory masyarakat terhadap bangunan cagar budaya ini dapat membantu usaha preservasi bangunan. Masyarakat sebagai saksi yang menyaksikan setiap perubahan yang terjadi dapat menjadi agen pengontrol dalam usaha pelestarian bangunan cagar budaya di Kota Palopo.

\section{Simpulan}

Salah satu bentuk keterikatan seseorang terhadap cagar budaya ialah adanya ingatan, kepercayaan, pemaknaan dan pengetahuan terhadap suatu tempat tertentu, sehingga menjadikan tempat tersebut penting bagi dirinya. Bentuk keterikatan tersebt dapat dilihat dari aspek kognisi yaitu pengethaun mengenai suatu tempat yang bersumber dari ingatan atau memorinya (place memory).

Bentuk place memory masyarakat terhadap bangunan cagar budaya dapat diidentifikasi dari karakterisitik bangunan yaitu lokasi, fungsi dan karakterisitik fisiknya. Hasil dari place memory ini pun ditunjukkan dari aspek afeksi yaitu adanya keinginan untuk melindungi tempat tersebut. Hal ini dapat menjadi rekomendasi bagi peerintah dalam suaha pelestarian bangunan agar budaya di Kota Palopo.

\section{Ucapan Terima Kasih}

Penelitian ini terlaksana atas bantuan dari dana hibah penelitian dari Direktorat Riset dan Pengabdian Masyarakat. Serta partisipasi dari mahasiswa Fakultas Teknik Fira Amir P. dan Nenang sebagai surveyor dalam kegiatan penelitian ini.

\section{Daftar Pustaka}

Akbar, Hidayatul \& Sudikno, Antariksa \& Meidiana, Christia. (2017). Memori Kolektif Kota Bima Dalam Bangunan Kuno Pada Masa Kesultanan Bima: Sebuah Studi sebagai Langkah Awal Pelestarian Sejarah. The Indonesian Green Technology Journal (IGTJ), vol 6, pp 8-18.

Damayanti, Rully. (2005). Kawasan "Pusat Kota” Dalam Perkembangan Sejarah Perkotaan Di Jawa. Dimensi Teknik Arsitektur Vol. 33, No. 1, pp $34-42$.

Nurhijrah. (2016). Place Attachment Masyarakat Tana Luwu Dataran Rendah Pada SitusSitus Kedatuan Luwu Periode Islam. Tesis Program Magister. Institut Teknologi Bandung.

Lewicka, M. (2008). Place attachment, place identity, and place memory: Restoring the forgotten city past. Journal of Environmental Psychology. Vol 28, no. 3, pp 209-231.

Lewicka, M. (2005). Ways to Make People Active: The Role of Place Attachment, Cultural Capital, and Neighborhood Ties. Journal of Environmental Psychology, Vol 25, pp 381395.

Paez, D. (2013). Social processes and collective memory: A cross-cultural approach to remembering political events, Collective memory of political events, Psychology Press pp 159-186.

Saldaña, J. (2015). The Coding Manual for Qualitative Researchers. Sage.

Stedman, R. C. (2003): Sense of Place And Forest Science: Toward A Program of Quantitative Research. Forest Science, 49, 822-829.

Utami, Wahyu. (2004). Kajian Stimulus Collective Memory terhadap Bangunan-Bangunan Kolonial di Sekitar Lapangan Merdeka. e-USU Repository. Medan: Universitas Sumatera Utara, 